\title{
O gasto público federal brasileiro: um perfil incrementalista?
}

\author{
Italo Fittipaldi \\ Universidade Federal da Paraíba (UFPB) \\ Saulo Felipe Costa \\ Universidade Estadual da Paraíba (UEPB) \\ Cletiane Medeiros Costa de Araújo \\ Universidade Federal de Pernambuco (UFPE)
}

A abordagem incrementalista pode explicar o comportamento do gasto social brasileiro nos últimos vinte anos? Objetivando responder a essa questão, o presente trabalho consistiu em estudo longitudinal exploratório do gasto público por função no Brasil. Recorreuse a medidas de desigualdade para a identificação da dispersão temporal da variável de interesse, bem como projeções do gasto social no médio prazo a partir da utilização de modelo dinâmico autorregressivo integrado e de média móvel (Arima). Observou-se que o gasto social apresentou um padrão incremental, no período de 1995 a 2014, e que essa característica se reproduzirá no médio prazo.

Palavras-chave: orçamento público, políticas públicas, execução orçamentária, gasto público, bem estar social

\section{El gasto público federal brasileño: un perfil incrementalista?}

El planteamiento gradual puede explicar el comportamiento del gasto social brasileño en los últimos veinte años? Con el objetivo de responder a esta pregunta, este estudio consistió en estudio longitudinal exploratorio de los gastos públicos según su función en Brasil. Se utiliza medidas de desigualdad para identificar la dispersión temporal de la variable de interés, así como las proyecciones del gasto social en el medio plazo a partir de la utilización del modelo dinámico autorregresivo integrado y de media móvil (Arima). Se observó que el gasto social mostró un patrón incremental, de 1995 a 2014, y que esta característica se reproduce en el medio plazo.

Palabras clave: presupuesto público, políticas públicas, ejecución presupuestaria, gasto público, bienestar social

[Artigo recebido em 1ㅇ de março de 2016. Aprovado em 28 de março de 2017.] 


\section{Brazilian federal public spending: an incremental profile?}

The incrementalist approach can explain the Brazilian social spending behavior in the last twenty years? Aiming to answer this question, this study consisted of exploratory longitudinal study of public expenditure by function in Brazil. It used inequality measures to identify the temporal dispersion of the variable of interest, as well as projections of social spending in the medium term from the use of dynamic integrated autoregressive and moving average model (ARIMA). It was observed that social spending showed an incremental pattern, from 1995 to 2014, and that this feature will be reproduced in the medium term.

Keywords: public budget, public policy, budget execution, public expenditure, social welfare 


\section{Introdução}

Da década de 1960 até o final da década seguinte o modelo incremental de análise de políticas públicas transformou-se no paradigma por excelência dos estudos sobre o Estado em ação. Sua vertente de estudo do processo orçamentário se constituiu no primeiro esforço analítico para a formulação de uma teoria orçamentária, desfrutando ainda hoje de certa capacidade de explicação para o processo de orçamentação (DAVIS; DEMPSTER; WILDAVSKY, 1966; WILDAVSKY, 1992, 1979; SHARKANSKY, 1968). Todavia, as modificações na regulamentação do processo de elaboração orçamentária nos E.U.A. e as novas evidências empíricas derivadas das alterações legislativas, corroeram parte da capacidade analítica do incrementalismo (KAMLET; Mowery, 1983; STRAUSSMAN, 1988). Contudo, tais considerações são fruto de trabalhos empíricos voltados para a experiência norteamericana. E no Brasil? O modelo incremental pode explicar o comportamento orçamentário no tempo? Qual a tendência do gasto público social para os próximos anos?

Com vista a responder a tais questões este estudo se revestiu de uma natureza exploratória na observação dos dados, objetivando apenas a identificação do padrão de comportamento do gasto público no tempo e a previsão de sua trajetória futura ${ }^{1}$. Dada essa opção metodológica, não se constituiu escopo analítico a identificação de mecanismos causais ou relações de causalidade entre variáveis. A contribuição com a literatura empírica brasileira de Ciência Política, portanto, consiste na replicação de uma teoria (incrementalismo) - como definido por King $(1995,2003)$ - em busca de evidências empíricas da ocorrência de uma execução orçamentária incremental do welfare state brasileiro e na previsão de seu comportamento de médio prazo.

O trabalho foi estruturado em cinco seções, onde a primeira apresenta os aspectos morfológicos da abordagem do incrementalismo desconexo e, na segunda seção, descreve-se a lógica do processo de elaboração orçamentária à luz do modelo analítico incremental. Na terceira seção são apresentados os dados referentes à variável selecionada no período em estudo (1995-2014), com as análises derivadas de seu comportamento temporal. Já a quarta seção apresenta as projeções estimadas para o dispêndio de welfare para os próximos anos. Finalmente, a quinta e última seção consiste nas considerações finais do trabalho.

\footnotetext{
${ }^{1}$ Sobre as expectativas e motivações para a institucionalização da "função avaliação" de políticas públicas, cf. Farias (2005).
} 


\section{A concepção da oferta "marginal" de políticas públicas}

O estudo da tomada de decisão adquiriu contornos mais próximos do mundo real com a crítica à modelagem racional-abrangente que norteia as análises ancoradas no princípio da racionalidade irrestrita. As limitações cognitivas dos stakeholders e a complexidade das organizações restringem as escolhas ao nível subótimo de decisões, caracterizando o processo decisório como "satisfatório", em vez de otimizado (SIMON, 1971). O nível ótimo nesse processo apenas seria possível com o pleno conhecimento das consequências da decisão tomada, afastandose, portanto, do real universo dos atores sociais. Por seu turno, a complexidade organizacional exige que o decisor - imerso em racionalidade restrita - estabeleça uma hierarquização dos meios e fins, gerando conclusões equivocadas sobre a estratégia (escolha) mais adequada. Ou seja, a otimização no processo decisório, portanto, não se constitui no padrão observável na ação humana.

As limitações analíticas dos policy makers para depreender a realidade multifacetada do processo de formulação e execução de políticas, e a decorrente existência, entre os decisores, de variadas escalas de preferências por linhas de ação, resultam em políticas inconclusas, recorrentes e desconexas, caracterizando a intervenção estatal por um "incrementalismo desarticulado" (LINDBLOM, 1959; LINDBLOM, HIRSCHMAN, 1999; LINDBLOM, 2014). Não raro, grupos de decisores (stakeholders) ${ }^{2}$ divergem quanto ao formato da policy, desencadeando, entre outras disfunções, conflitos intraburocráticos em paralelo à execução da ação estatal, fazendo emergir um dissenso implementador ${ }^{3}$ que será mais agudo quanto mais complexo for o desenho e a natureza da política pública em curso. Com isso, o perfil do Estado em ação é caracterizado pela fragmentação, com as políticas públicas sendo executadas de maneira não linear, marginal, e sem a devida articulação organizacional, ao longo do tempo. O processo de "aproximações sucessivas" se constitui, assim, no padrão operacional para a definição do escopo e magnitude da oferta de políticas.

Adicionalmente, a complexidade operacional, a multiplicidade de burocratas envolvidos na produção da policy e a obscuridade do marco regulatório da intervenção multiplicam os "pontos de decisão" da política pública, induzindo problemas de coordenação no seu fornecimento, em razão dos dilemas de ação coletiva gerados no interior da estrutura implementadora. A multiplicidade dos pontos de decisão e a subsequente diversificação de preferências entre os stakeholders retardam

\footnotetext{
${ }^{2}$ Lindblom (1999) utiliza o termo partidário para classificar indivíduos e/ou grupos que tomam partido acerca da formulação e implementação de uma política pública, ou não. Utiliza-se aqui, portanto, a expressão grupos de interesses no mesmo sentido que Lindblom utiliza o termo partidário.

${ }^{3}$ Neste trabalho o termo dissenso implementador e conflitos de poder, derivado de problemas de coordenação na execução de políticas, serão tratados como sinônimos.
} 
significativamente a conclusão dos programas governamentais, tornando a incompletude a marca registrada da ação estatal (PRESSMAN; WILDAVSKY, 1973 [1998]).

A probabilidade de não fragmentação (completude) de uma política, portanto, caminha na razão direta da superação dos problemas de coordenação derivados da formulação e da operacionalidade emergentes de um ambiente caracterizado pela insuficiência analítica e diversidades de estratégias executoras. Dada essa dinâmica conflituosa no processo de sua produção, as políticas públicas consistem em incrementos de iniciativas precedentes de ações governamentais, executadas com expansões marginais no tempo.

Percebe-se que tanto na análise lindbloniana quanto na abordagem de Pressman e Wildavsky os problemas da coordenação de políticas - i.e. os conflitos de poder existentes no interior da estrutura organizacional de decisão (execução) da política - transformam-se no leitmotiv do incrementalismo nas ações governamentais. Isso torna extremamente incomuns as mudanças bruscas e rápidas na oferta de políticas públicas, fazendo com que o fornecimento de políticas apresente um perfil temporal pouco substantivo e com variações executadas em margens muito estreitas em relação às ações governamentais precedentes, embora crescentes no tempo. Em outros termos, a abordagem incrementalista identifica a existência de uma natureza parcimoniosa na oferta de políticas públicas, admitindo uma "acomodação" da burocracia estatal a padrões de intervenção observada em períodos anteriores.

Diante disso, o conflito de poder em que se caracteriza o processo de formulação e implementação de políticas materializa-se efetivamente na elaboração e execução orçamentária ${ }^{4}$, onde as opções que irão compor a cesta de policies ofertada às diversas clientelas e expressa em volumes de recursos disponibilizados para tal finalidade nas rubricas do orçamento público, reproduzem níveis precedentes de gasto. Considerando essa análise, o processo orçamentário apresenta um perfil de regularidade temporal, desde que não ocorram alterações significativas na demanda subjacente por determinadas políticas públicas ${ }^{5}$.

\footnotetext{
${ }^{4}$ À guisa de simplificação analítica, a formulação e a execução do orçamento governamental serão tratadas aqui como etapa única do processo orçamentário.

${ }^{5}$ Nesse limite, Baumgartner e Jones (1993) ressaltam a lógica de interação dos subsistemas político e comportamental que permeiam a formulação/decisão de uma agenda política, a exemplo do orçamento público (agenda-based model). O modelo de equilíbrio pontuado formulado pelos autores destaca que, embora a racionalidade limitada na tomada de decisão associada às restrições institucionais favorece a existência de longos períodos de estabilidade, o ambiente político também pode ser (menos) frequentemente pontuado por grandes mudanças em decorrência de forças exógenas e endógenas (mudanças na sociedade, no governo, crise econômica) que, por sua vez, podem alterar significativamente as regras de decisão e, consequentemente, as prioridades políticas. Todavia, a crítica que geralmente se faz a esse modelo analítico diz respeito ao pouco poder preditivo quanto à ocorrência de rupturas (pontuações).
} 
É a atuação negociada dos grupos de interesses, e a inexistência de "perdedores universais" no processo de definição de políticas, que possibilita a regularidade, no tempo, dos recursos orçamentários. Ao ancorar-se na concepção pluralista das relações de poder societal, a corrente incrementalista incorpora à sua análise um conjunto de premissas importadas da economia clássica em que se fundamenta, admitindo (i) o atomismo dos grupos de interesses; (ii) a capacidade homogênea de arregimentar recursos de poder e assim influenciar efetivamente a oferta de políticas; e (iii) o intervencionismo estatal assegurando o livre funcionamento dos grupos organizados, garantindo o resultado dos embates travados entre as lideranças sociais.

Nesse caso, cabe ao Estado o papel de balizador das relações de poder, exercendo função semelhante à do sistema de preços no mercado de concorrência perfeita ao garantir o resultado social advindo do conflito distributivo entre os atores. 0 funcionamento desse "mercado de políticas públicas" é o que garante o equilíbrio de bem-estar social, afastando mudanças bruscas ou revolucionárias com elevados custos sociais (i.e., ineficiência sistêmica) ${ }^{6}$. Porém, ao destacar o conflito distributivo existente entre grupos de interesses, a visão pluralista traz em cena a negociação como característica essencial ao funcionamento das escolhas sociais, por caracterizarse como instrumento de controle recíproco (DAHL; LINDBLOM, 1971).

É essa necessidade de negociação entre os grupos com vistas ao benefício (e controle) mútuo que conduz - em condições dadas - à possibilidade de equalizar a oferta de policies e gerar estabilidade no volume e no alcance das ações governamentais ao longo do tempo, dotando determinada política pública de um "legado temporal". O Estado em ação - particularmente as ações de welfare - caracteriza-se pela variação marginal, em objetivo e abrangência/volume, das políticas entregues às diferentes clientelas, resultado de um ajuste mútuo entre os diversos grupos, refletindo, dessa forma, um modelo estrutural de sociedade (ETZIONI, 2014). Sob essa lógica funcional, ficam reduzidos os custos da busca por informação e o custo do cálculo estratégico para a definição da ação a ser tomada, atrelando o equilíbrio do bem-estar social à capacidade de cooperação entre grupos em torno de uma determinada política pública. A "cooperação" nesse caso - para este trabalho - não resulta exclusivamente de consenso entre as ações de políticas a serem empreendidas, mas, em sentido mais amplo, da incapacidade de um grupo de impor aos demais suas preferências alocativas ${ }^{7}$.

\footnotetext{
6 Em outros termos, "tomados em conjunto esses pressupostos são um pouco mais adequados ao modelo da mão invisível de Adam Smith aplicado à política, onde o grupo é o empresário e o equilíbrio não está no menor preço, mas no interesse público" (LoWI, 1979, p. 51).

7 Crítica às teorias pluralistas, cf. Schmitter, 1979; Lehmbruch, 1979. Para uma análise do corporativismo no Brasil, ver Diniz (1997).
} 
O equilíbrio potencial entre os "partidários" em influenciar a dimensão e o escopo da oferta de políticas transforma o orçamento estatal no resultado das escolhas sociais negociadas e geradoras do bem-estar societal, tornando as variações nos recursos orçamentários dotadas de natureza pouco volátil. Mas, como se processa a orçamentação desse equilíbrio societal? Para responder a essa questão se faz necessária uma exposição sinóptica da lógica subjacente do processo de formulação e execução do orçamento governamental, sob as lentes do incrementalismo desconexo.

\section{Conflito de interesses e a lógica do orçamento incremental: a emergência de um padrão cooperativo}

Em termos gerais, o processo orçamentário consiste em uma programação ou planejamento de despesas futuras, resultado de escolhas sociais feitas no presente, com base em expectativas quanto, e.g., à evolução da receita de tributos e o comportamento da taxa de inflação no período da realização do gasto governamental orçado. Expectativas divergentes quanto ao volume de tributos arrecadados e ao comportamento geral dos preços, bem como preferências distintas sobre objetivos dos gastos e tipos de despesas, produzem tensões entre grupos de interesses concernentes à formulação e execução orçamentária, transformando o arcabouço legal do orçamento no resultado tangível das negociações entre grupos.

Portanto, o processo orçamentário resulta da ação de barganha entre atores sociais, necessária para o "acordo" de (re)distribuição dos recursos escassos, sob a direção do setor estatal que, mediante essa atuação, define o grau de intervenção e o peso relativo do Estado na produção da riqueza nacional ou regional. Todavia, o fato do orçamento público resultar das negociações entre grupos de interesses não deve eclipsar a magnitude e a complexidade das estratégias adotadas (ou negligenciadas) ao longo dos acirrados embates travados com vistas ao delineamento da oferta de políticas e de seus financiamentos.

Essa complexidade decisória, ao refletir a geometria variável do conflito distributivo entre grupos organizados, e a dimensão multifacetada da atuação de atores sociais visando benefícios públicos, restringida pelo tempo e normatização que regulamentam a formulação da peça orçamentária, responde pela expansão limitada - embora contínua - do orçamento público nos diferentes períodos fiscais. A dificuldade de parametrizar ex-ante os reais impactos advindos das opções de políticas e dos méritos de programas elaborados, possibilitando uma análise comparativa que estabelecesse uma escala de prioridades das ações governamentais, desloca para o processo de negociação a definição do que é ou não prioritário para determinado período. 
Incapazes de definir uma função de utilidade agregada das políticas públicas, os grupos canalizam recursos para o conflito distributivo travado ao longo do processo orçamentário visando influenciar a definição da oferta e das fontes monetárias de policies específicas, gerando tensões decisórias que se "acomodam" pela opção de se reproduzir decisões orçamentárias prévias. Em outras palavras, para superarem (reduzirem) os obstáculos existentes no processo de negociação do escopo e dimensão das políticas, utiliza-se como parâmetro o orçamento anterior e o legado de políticas iniciadas, sendo o método incremental o vetor de fomento da ação cooperativa na elaboração orçamentária (DAVIS; DEMPSTER; WILDAVSKY, 1966).

A disputa pelas prevalências de demandas quando da formulação do orçamento conduz a certo "ponto de equilíbrio" entre as reivindicações manifestas, ao se reproduzir padrões decisórios anteriores. Essa lógica orçamentária é modificada apenas na ocorrência de eventos aleatórios de forte impacto para a (re)distribuição de recursos entre os grupos de interesses, quando o incrementalismo que a caracteriza é abandonado até que uma nova lógica incremental seja estabelecida agora em um novo patamar de alocação de recursos. O processo incremental de alocação de recursos inicia-se outra vez, até que um novo acontecimento de grande monta acirre o conflito distributivo.

Destarte, quanto mais regular for as incidências de eventos com repercussões expressivas sobre o quadro socioeconômico de uma nação/região, menos eficiente é o processo de orçamentação em virtude da inexpressiva capacidade de ações cooperativas entre os grupos, comprometendo a oferta exitosa de políticas públicas. Isso explica, para alguns estudiosos, a ineficiência e o desperdício de recursos existentes no processo de planejamento e elaboração orçamentária realizados em países pobres (CAIDEN; WILDAVSKY, 1974) ${ }^{8}$.

\section{Ambiente político-econômico e o comportamento temporal do gasto público}

Entre 1995 e 2014, e sob a égide de certa estabilidade macroeconômica, o Brasil experimentou ao menos sete importantes processos políticos que, dada a sua potencial natureza (re)distributiva, poderiam redimensionar a alocação dos recursos públicos e redefinir a oferta de políticas: 1) cinco eleições presidenciais ${ }^{9}$; 2) iniciativas de reforma na administração pública; e 3) um esforço de adequação de ações governamentais à crise econômica internacional dos últimos cinco anos. Os ciclos eleitorais, ao produzirem alternância efetiva de poder entre grupos políticos antagônicos, tornam possíveis diferentes configurações relativas ao

\footnotetext{
${ }^{8}$ Para críticas à abordagem incrementalista cf. O’Connor (1973), Wanat (1974), Jones, True e Baumgarten (1997), True (2000).

${ }^{9}$ Eleições presidenciais de 1998, 2002, 2006, 2010, e 2014.
} 
escopo e magnitude da despesa pública que se materializam no estabelecimento de padrões de intervenção estatal diferenciados (BORSANI, 2003). Os embates entre as escolhas exequíveis de (re)definição da oferta de políticas públicas, inerentes aos ciclos eleitorais, per se, se constituem um processo de tomada de decisão acerca da manutenção ou modificação da trajetória temporal das políticas ${ }^{10}$.

Por seu turno, as políticas de reestruturação da administração pública da década de 1990 trouxeram em seu bojo as tensões inerentes às ações concomitantes de elevação da eficiência do gasto público e de descentralização de recursos via mudança institucional. Para parte da literatura as reformas de cunho gerencial no setor público - e sua reprodução mimética nos entes subnacionais - foram vítimas do problema da falha sequencial das reformas administrativas, tornando fragmentado o resultado efetivo desse empreendimento de política pública (MATIAS-PEREIRA, 2008; Abrúcio, 2007; REZENDE, 2004).

Para além da real efetividade daquele empreendimento gerencial, impossível ignorar que foi executado um programa de ajuste fiscal com a magnitude necessária para debelar o descontrole das contas públicas herdado do período de hiperinflação. A implementação de políticas de controle orçamentário e aumento da eficiência fiscal, para além do real avanço na dimensão da mudança institucional da reforma administrativa brasileira à época, permeou o ambiente decisório, fazendo com que a natureza diferenciada das políticas públicas reformadoras e o antagonismo operacional que caracterizam suas estratégias de execução se constituíssem em foco de tensões, barganha e negociações políticas, com efeitos potenciais diretos sobre a configuração orçamentária.

Não menos importante foi a adoção de medidas de política econômica objetivando mitigar o impacto da crise econômica internacional a partir de 2009. A estratégia adotada de expansão da demanda agregada via relaxamento no superávit primário, que permeou o primeiro Governo Dilma Rousseff, dado o pífio efeito sobre o ritmo de atividade econômica, produziu nova configuração de poder no interior de seu governo. Isso levou à execução de ações restritivas do papel do gasto federal como vetor de crescimento econômico, conduzindo a redefinições acerca do perfil e do escopo da alocação de bens e serviços. A trajetória temporal do welfare state brasileiro, segundo a lógica de ajustes fiscais e da necessidade de recompor a magnitude perdida do superávit primário, portanto, seria de inflexão para os próximos anos, descaracterizando a vigência de um padrão incremental de despesa nessa área de atuação do Estado ao longo do tempo. Mas, como se comportou o gasto público brasileiro nos últimos 20 anos? Projeções do gasto social apontam para uma reversão da trajetória observada nos últimos 20 anos?

\footnotetext{
${ }^{10}$ Desnecessário dizer que os conflitos de interesses subjacentes a esse processo forjam uma geometria variável dos conflitos de poder (i.e., definição dos bens públicos ofertados) transportada para o orçamento público.
} 


\section{O gasto por função do Estado e a estratégia empírica de identificação de seu comportamento}

A análise agregada do gasto público, ou mesmo uma desagregação mais acentuada, limita a percepção acerca das escolhas preferenciais de alocação dos recursos públicos no tempo e a identificação de possíveis padrões de cooperação entre grupos societais acerca da partilha de tais recursos. Se o orçamento público resulta das negociações políticas intra e intergrupos, a observação do dispêndio governamental por função do Estado possibilita apontar as áreas de atuação estatal onde se observa regularidade temporal na oferta de policies. Inicialmente foram discriminadas as áreas de atuação do Estado, objeto da despesa pública por função, com o nível de agregação que possibilitasse a categorização do dispêndio governamental como gasto mínimo, gasto econômico e gasto social (chamase atenção do leitor para o fato de que neste trabalho não foram consideradas as despesas com juros). Por meio de corte longitudinal abarcando o período 1995 a 2014, foram selecionadas variáveis indicativas da intervenção estatal para compor o mosaico analítico do padrão evolutivo do gasto público federal brasileiro (Quadro 1). Os valores do gasto público por função foram transformados a preços constantes de 2014, atualizados monetariamente pelo Índice de Preços ao Consumidor Amplo (IPCA).

\section{Quadro 1 - Gasto público por funções do Estado}

\begin{tabular}{|c|c|c|}
\hline Gastos Mínimos & Gastos Sociais & Gastos Econômicos \\
\hline & & Agricultura \\
& & Ciência e Tecnologia \\
& & Comércio e Serviços \\
& & Comunicações \\
Administração & Assistência Social & Desenvolvimento Regional \\
Defesa Nacional & Cultura & Desporto e Lazer \\
Essencial à Justiça & Educação & Direitos da Cidadania \\
Judiciário & Previdência Social & Energia \\
Relações Exteriores & Saneamento & Gestão Ambiental \\
Segurança Pública & Saúde & Habitação \\
& & Indústria \\
& & Organização Agrária \\
& & Trabalho \\
& & Transporte \\
& & Urbanismo \\
\hline
\end{tabular}

Fonte: Elaborado pelos autores a partir de Rezende (1996). 


\section{Categorizando o que é "incremental"}

Um passo importante na identificação do incrementalismo no gasto público consiste em definir quantitativamente o que será considerado "incremental". Oscilações marginais na despesa precisam ser mensuradas a partir de medidas que possibilitem captar o tamanho da desigualdade na execução orçamentária ao longo do tempo. Porém, tal medida precisa ser acompanhada da identificação da tendência da despesa no tempo. Ou seja, além da medição da assimetria do gasto efetivo, é necessário identificar se determinada modalidade de dispêndio registrou aumento ou redução no tempo.

Para o mapeamento do escopo de atuação do Estado brasileiro no período em tela, recorreu-se em seguida a medidas estatísticas que viabilizassem captar possíveis disparidades no gasto público por função ao longo do tempo, sob a lógica de indicadores de escala. Optou-se, assim, pela adoção do coeficiente Gini por ser uma medida de ampla utilização na literatura que aborda medições de desigualdade. Contudo, a sensibilidade do coeficiente Gini aos valores centrais da distribuição o torna menos eficaz quando se deseja captar as disparidades entre valores que se encontram à esquerda da curva de distribuição de dados, ou seja, baixos valores absolutos. Visando preencher essa lacuna em uma análise centrada apenas no Gini, recorreu-se a medidas de entropia, como o índice de Theil-T. Assim, o índice de Theil-T mede o quanto o gasto público observado se afastou de uma distribuição perfeitamente uniforme. Acredita-se, portanto, que a utilização dessas medidas de desigualdade conjuntamente tornou possível captar o grau de volatilidade da despesa por área de atuação do Estado ao longo da série histórica selecionada.

Ambos os indicadores apresentam escalas que variam entre 0 e 1 , onde quanto mais próximo de zero, menor é a concentração dos valores de determinada variável, ou seja, menor é a desigualdade. Por outro lado, quanto mais próximo da unidade, maior é a desigualdade na distribuição de dados. Aplicando esses índices para os valores reais absolutos de execução orçamentária por função, obtiveram-se os resultados do perfil do dispêndio nos últimos 20 anos, exibidos na Tabela 1.

Nas duas últimas décadas o gasto mínimo apresentou maior disparidade ao longo dos anos, exibindo padrão totalmente diferenciado das demais naturezas do gasto público federal. Essa modalidade de dispêndio apresentou um coeficiente Gini duas vezes superior ao registrado pelos demais e um índice de Theil-T de quatro a sete vezes acima do gasto social e do gasto econômico, respectivamente. Por outro lado, o gasto econômico mostrou-se aquele com menor volatilidade nos últimos 20 anos, sendo acompanhado nesse padrão temporal pelo gasto social, embora em nível superior de disparidade. A dimensão do coeficiente Gini e do índice de Theil-T aponta para um padrão de intervenção estatal mais regular nos valores destinados às funções de Estado na área social e econômica do que em sua atividade mínima. Chega a ser contraintuitivo que aqueles tenham se mostrado mais regulares que o gasto mínimo. 
Tabela 1 - Nível de desigualdade temporal do gasto público - 1995 a 2014

\begin{tabular}{c|c|c}
\hline \multirow{2}{*}{ Natureza do Gasto } & \multicolumn{2}{|c}{ Medida de Desigualdade } \\
\cline { 2 - 3 } & Gini & Theil-T \\
\hline Mínimo & 0.357 & 0.258 \\
Social & 0.187 & 0.053 \\
Econômico & 0.152 & 0.036 \\
\hline
\end{tabular}

Fonte: Elaborado pelos autores a partir de dados da Secretaria do Tesouro Nacional/Ministério da Fazenda.

Contudo, ao se observar a trajetória no tempo da execução orçamentária (valores absolutos reais), constata-se que o gasto econômico, cujas medidas de desigualdade foram as mais baixas entre as naturezas de dispêndio, apresentouse com padrão de estabilidade temporal. As oscilações ao longo da série histórica fizeram que essa modalidade de despesa chegasse em 2014 com praticamente o mesmo volume de execução orçamentária que em 1995, não registrando assim uma tendência nem ascendente, nem decrescente. Uma possível categorização dessa modalidade de despesa como "incremental", se forem considerados apenas os valores do coeficiente Gini e do índice de Theil-T, acredita-se, contrasta com o perfil exibido pelo gasto econômico no tempo, já que incrementalismo não é sinônimo de estagnação na execução orçamentária (DAVIS; DEMPSTER; WILDAVSKY, 1966). De fato, apenas o gasto social, com uma tendência nítida, porém regular e gradual, permite a categorização de incremental, haja vista a combinação de uma baixa medida de desigualdade associada a uma trajetória definida ao longo da série histórica (Gráfico 1).

Gráfico 1 - Trajetória do gasto público por função do Estado (mínimo, social, econômico) - 1995 a 2014 (valores em escala logarítmica)

LN_Gast_Min

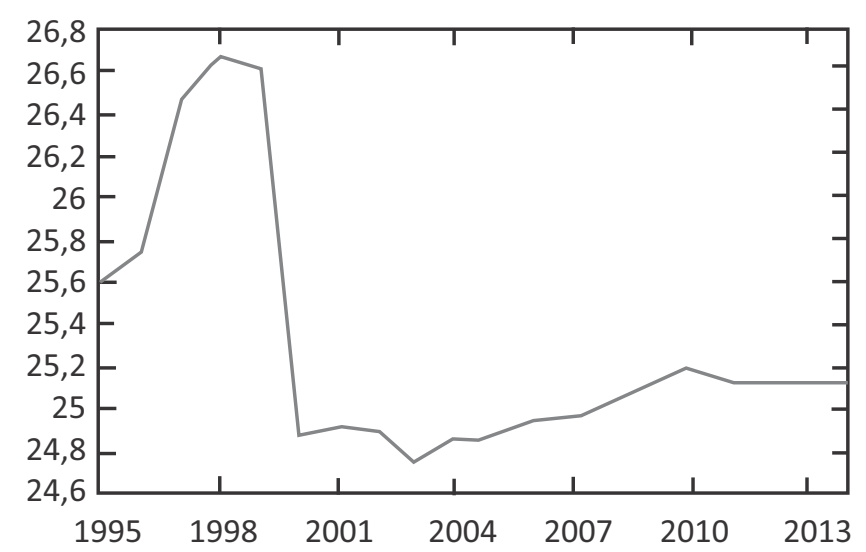


LN_Gast_Soc

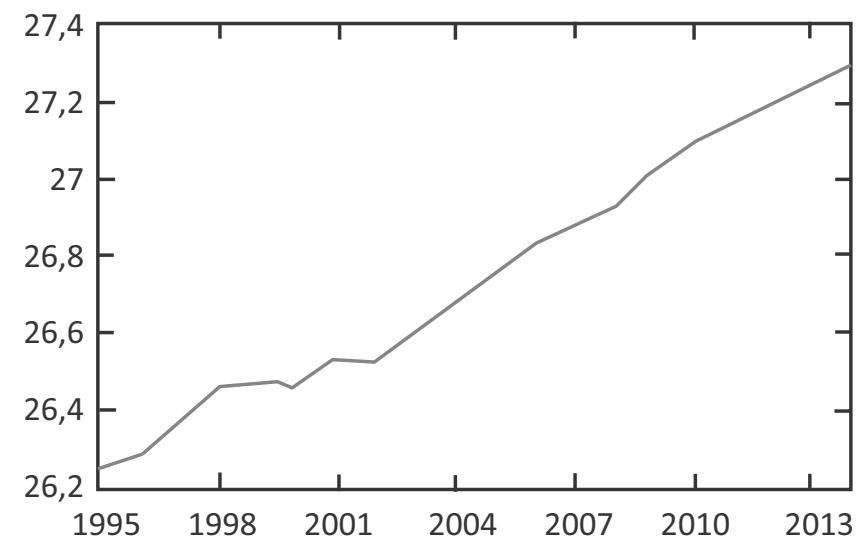

LN_Gast_Econ

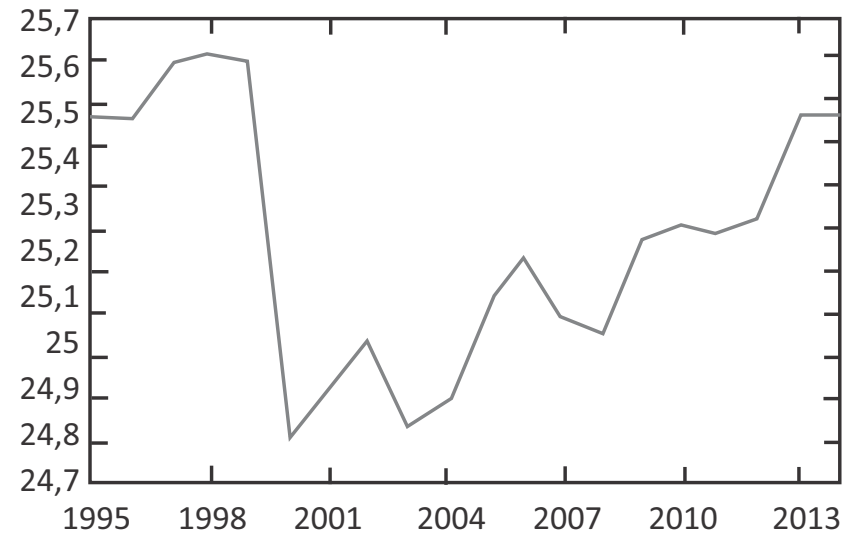

Fonte: Elaborado pelos autores a partir de dados da Secretaria do Tesouro Nacional/Ministério da Fazenda.

A estratégia analítica de combinar medidas de desigualdade com a tendência observada na despesa possibilitou identificar divergência entre os padrões de intervenção estatal, viabilizando uma categorização mais precisa do que é ou não um perfil incremental de gasto público (Tabela 2).

Tabela 2 - Comportamento do gasto público por função - 1995 a 2014

\begin{tabular}{c|c|c|c|c}
\hline \multirow{2}{*}{$\begin{array}{c}\text { Natureza do } \\
\text { Gasto }\end{array}$} & \multirow{2}{*}{ Tendência } & \multicolumn{2}{|c|}{ Medidas de Desigualdade } & \multirow{2}{*}{$\begin{array}{c}\text { Padrão } \\
\text { Incremental }\end{array}$} \\
\cline { 3 - 4 } & & Gini & Theil-T & Não \\
\hline Mínimo & Redução & 0.357 & 0.258 & Sim \\
Social & Crescimento & 0.187 & 0.053 & Não \\
\hline Econômico & Estabilidade & 0.152 & 0.036 & \\
\hline
\end{tabular}

Fonte: Elaborado pelos autores. 
O perfil do gasto social brasileiro parece resultar de um legado prévio de políticas (policy feedback) decorrente da emersão de padrões cooperativos em torno da magnitude do orçamento e do escopo dessa área de atuação do Estado ${ }^{11}$. A decisão de gasto no presente reproduziu o gasto passado, com aumentos regulares, mas com variabilidade reduzida, dando um contorno incremental à construção da rede social de proteção no Brasil. Os dados, portanto, parecem apontar para o fato de que nas duas últimas décadas o welfare state brasileiro foi erigido para além dos matizes ideológicos do governo de plantão, como resultado da geometria variável nas negociações políticas em torno do tema. Afinal, "a política (política prévia) pode definir o poder político por meio da definição da agenda pública, padrões de conflito de grupos de interesse, influência ou mudança nas regras formais, definição prévia de alocação de recursos, capacidade incremental, etc." (SÁTYRO, 2006, p. 72. Grifo nosso). Contudo, qual a previsão do comportamento do gasto social para os próximos anos? Verificar-se-á o mesmo padrão de crescimento incremental? Buscou-se responder a tais questões na próxima seção.

\section{Para onde caminha o gasto com welfare no Brasil?}

Considerando que nas duas últimas décadas o gasto social brasileiro apresentou um perfil incremental, como resultado do legado de políticas prévias, buscou-se, a partir de projeções da execução orçamentária desse dispêndio, verificar se as configurações de forças políticas que o definiram como incremental se mantêm no tempo. Para o mapeamento dessa trajetória futura recorreu-se à análise dos dados sob o esquema dos modelos dinâmicos com processo autorregressivo integrado e de média móvel (Arima).

Gráfico 2 - Função de autocorrelação (FAC) e função de autocorrelação parcial (FACP) do gasto social do Brasil (1995 a 2014)

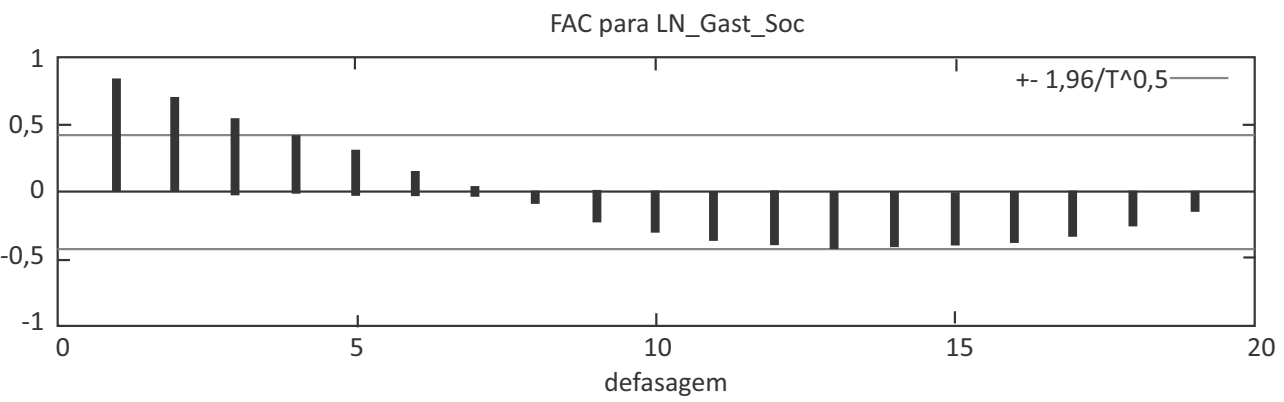

\footnotetext{
${ }^{11} \mathrm{Em}$ instigante análise, Arretche (2004) evidencia os problemas de coordenação e autonomia sobre as relações federativas na gestão de políticas sociais no Brasil.
} 
FACP para LN_Gast_Soc

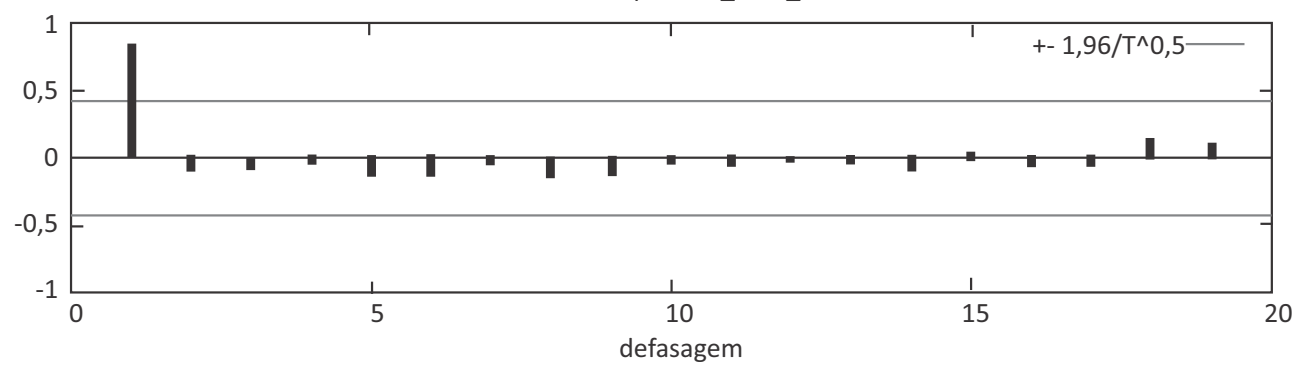

Entretanto, a série original do gasto social não é estacionária em nível. A análise do correlograma da função de autocorrelação (FAC) e da função de autocorrelação parcial (FACP) - juntamente com seus intervalos de confiança - revelou que a série em estudo torna-se estacionária apenas quando integrada em segunda ordem (Gráfico 2). Diante disso, o modelo de estimação foi definido como Arima $(2,2,3)$, com termo constante. Por sua vez, visando não suavizar as oscilações na série (dessazonalização), optou-se por não incluir variáveis dummies nos modelos de regressão. Assim, procedendo à estimação dos parâmetros do modelo Arima $(2,2,3)$ pelo método OLS (ordinary least squares), foram obtidos os coeficientes e seus respectivos testes de significância, conforme exposto na Tabela 3.

Tabela 3 - Modelo estimado para o gasto social - Arima $(2,2,3)$

\begin{tabular}{|c|c|c|c|c|}
\hline Parâmetros & Coeficientes & $\begin{array}{l}\text { Erro- } \\
\text { Padrão }\end{array}$ & $\mathbf{z}$ & $p$-valor \\
\hline Constante & 0.001018 & 0.0012381 & 0.823 & 0.4108 \\
\hline$\phi 1$ & $-1.360500 * * *$ & 0.186392 & -7.299 & 0.0000 \\
\hline$\phi 2$ & $-0.652064 * * *$ & 0.167930 & -3.883 & 0.0001 \\
\hline$\vartheta 1$ & $0.982843 * * *$ & 0.369071 & 2.663 & 0.0077 \\
\hline$\vartheta 2$ & $-0.982842 * * *$ & 0.315068 & -3.119 & 0.0018 \\
\hline$\vartheta 3$ & $-1.000000 * * *$ & 0.368948 & -2.710 & 0.0067 \\
\hline Média da var. dependente & 0.000002 & & & \\
\hline Média de inovações & -0.001576 & & & \\
\hline Desvio-padrão var. dependente & 0.046490 & & & \\
\hline Desvio-padrão das inovações & 0.022443 & & & \\
\hline Log da verossimilhança & 38.60863 & & & \\
\hline Critério de Schwarz & -56.98466 & & & \\
\hline Critério de Akaike & -63.21726 & & & \\
\hline Critério de Hannan-Quinn & -62.35787 & & & \\
\hline Número de Observações & 20 & & & \\
\hline
\end{tabular}




\begin{tabular}{c|c|c|c|c}
\hline Parâmetros & Coeficientes & $\begin{array}{c}\text { Erro- } \\
\text { Padrão }\end{array}$ & z & p-valor \\
\hline
\end{tabular}

Teste LM para autocorrelação

$$
\begin{aligned}
& H_{0}=\text { sem autocorrelação } \\
& \chi^{2}(2)=0.43648 \\
& \text { Ljung-Box } Q=0.8039
\end{aligned}
$$

Fonte: Elaboração dos autores.

* Estatisticamente significativo no nível de 1\%. Estimação usando filtro de Kalman (Máxima Verossimilhança Exata) e erros padrão baseado na Hessiana.

O bom ajustamento do modelo pode ser comprovado no Gráfico 3 a seguir, que exibe a normalidade dos resíduos do modelo Arima (2,2,3). Observada a adequação da escolha do modelo de estimação, na sequência se projetou o comportamento futuro do gasto social no Brasil para um horizonte de médio prazo (próximos seis anos) e foi possível detectar uma "tendência incremental crescente" dessa modalidade de despesa (Gráfico 4). Os dados parecem apontar - ceteris paribus - para a manutenção do padrão cooperativo nas arenas decisórias acerca da construção da rede social de proteção no Brasil. Para o médio prazo, portanto, espera-se a manutenção da trajetória crescente, regular e gradual da despesa de welfare no país.

\section{Gráfico 3 - Normalidade dos resíduos do modelo Arima(2,2,3)}

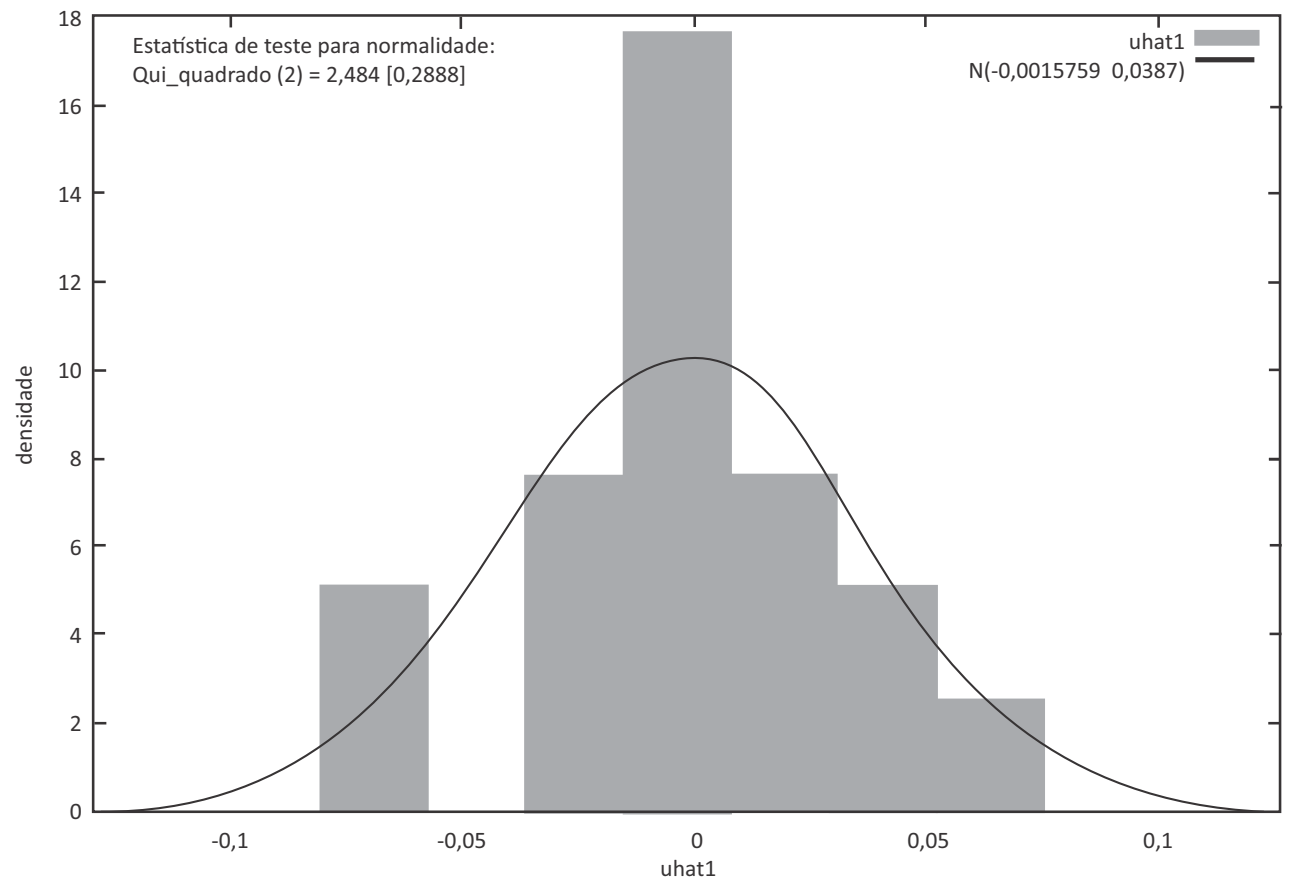

Fonte: Elaborado pelos autores. 
É importante destacar que a estimação do gasto social para os próximos seis anos foi realizada em escala logarítmica, pois o objetivo primário da projeção não foi identificar valores absolutos dessa modalidade de despesa, mas, antes, identificar a trajetória no tempo. Assim, percebeu-se que a curva do gasto social, ceteris paribus, manterá as mesmas características das duas últimas: tendência ascendente com crescimento regular e gradual.

\section{Gráfico 4 - Projeção para o gasto público social até 2020}

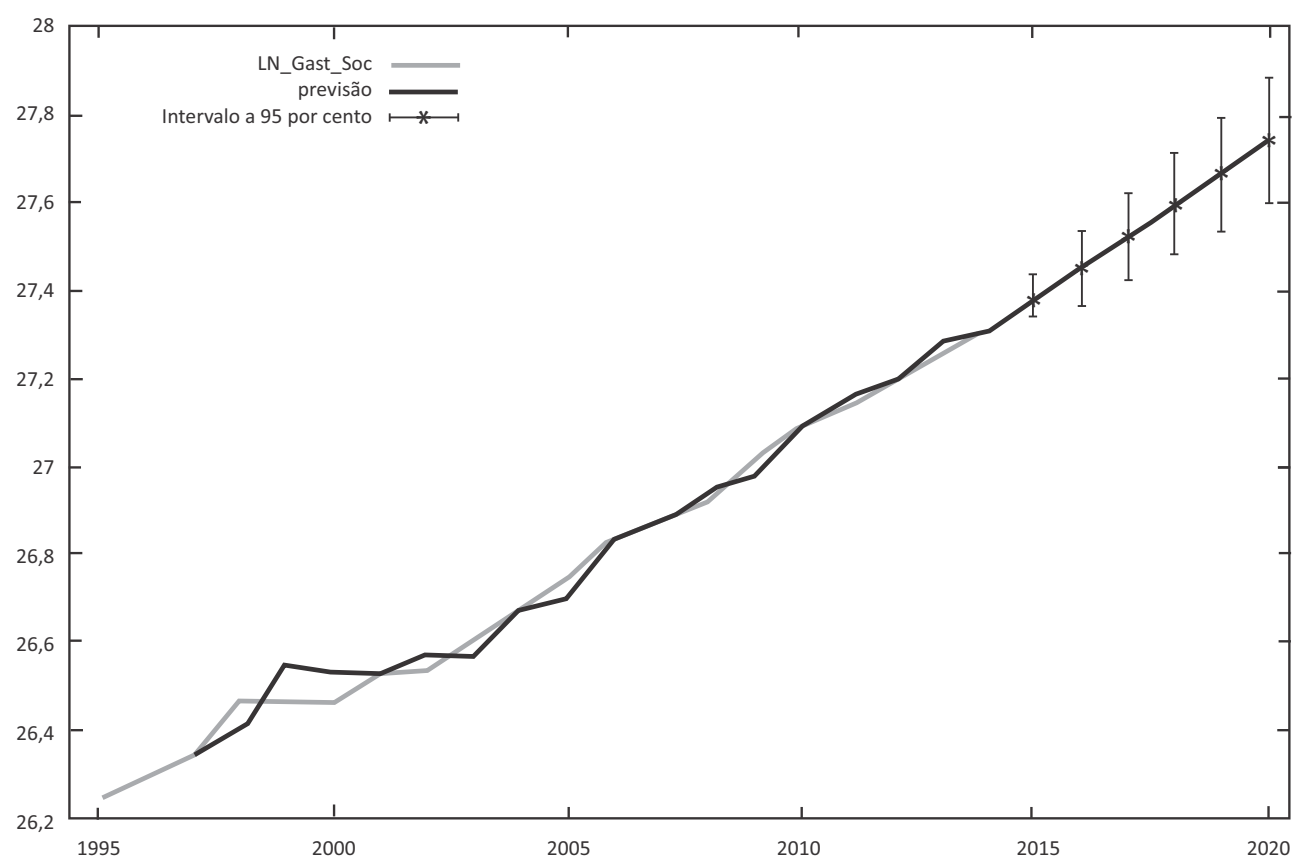

Fonte: Elaborado pelos autores.

\section{Considerações finais}

Este trabalho consistiu em uma análise exploratória do comportamento do gasto público federal brasileiro no período de 1995-2014, focalizando na despesa de welfare, com vistas à testabilidade da abordagem incrementalista no gasto público social brasileiro, e a estimação de seu comportamento futuro. Destarte, observouse que o gasto econômico e o gasto social registraram as menores assimetrias na execução orçamentária nos últimos vinte anos. Contudo, a trajetória do gasto econômico manteve em 2014 praticamente o mesmo patamar registrado em 1995. Como a abordagem incrementalista não é sinônimo de estagnação orçamentária, essa natureza de dispêndio não foi categorizada como incremental, mas apenas o gasto social, em razão de uma nítida trajetória tendencial no tempo. 
Estimando o comportamento do gasto social para o médio prazo, por meio da utilização de modelo dinâmico com processo autorregressivo integrado e de média móvel (Arima), foi possível identificar, ceteris paribus, a manutenção de um padrão cooperativo nas arenas decisórias acerca dessa modalidade de despesa. Essa configuração no ambiente decisório parece ser capaz de manter o dispêndio de welfare no Brasil crescente, regular e gradual nos próximos anos.

Todavia, não sem reparos, chegou-se a tais considerações. A natureza meramente descritiva da pesquisa não possibilitou o pleno reconhecimento de causalidades, e de que variáveis interferiram - e em que magnitude - na configuração atual do gasto público no Brasil. A utilização de uma série temporal curta e a definição do recorte analítico sobre a categorização do que é incremental limitam as conclusões do trabalho. Ademais, recorreu-se à execução orçamentária para identificar padrões decisórios, em um esforço de "engenharia reversa" nos estudos sobre políticas públicas, o que irá requerer aperfeiçoamentos analíticos em estudos posteriores.

\section{Referências bibliográficas}

ABRúcıo, L. F. A trajetória recente da gestão pública brasileira: um balanço crítico e a renovação da agenda de reforma. RAP - Revista de Administração Pública, Edição Especial, p. 67-86, 2007.

ARRETCHE, M. Federalismo e políticas sociais no Brasil: problemas de coordenação e autonomia. São Paulo em Perspectiva. v. 18, n. 2, p. 17-26, 2004.

Baumgartner, F. R.; Jones, B. D. Agendas and Instabilities in American Politics. Chicago: University of Chicago Press, 1993.

BORSANI, H. Eleições e economia: instituições políticas e resultados macroeconômicos na América Latina (1979-1998). Belo Horizonte: UFMG; Rio de Janeiro: IUPERJ, 2003.

CAIDEN, N.; WILDAVSKY, A. Planning and budgeting in poor countries. New York: John Wiley \& Sons, 1974.

DAHL, R. A.; LindBlom, C. E. Política, economia e bem-estar social. Rio de Janeiro: Editora Lidador, 1971.

DaVIS, O. A.; Dempster, M. A. H.; WILdAVSKY, A. A theory of the budgetary process. The American Political Science Review, v. LX, n. 3, setembro, 1966.

DINIZ, E. Crise, reforma do Estado e governabilidade: Brasil, 1985-95. Rio de Janeiro: Editora FGV, 1997.

EtzıonI, A. Mixed scanning: uma "terceira" abordagem de tomada de decisão. In: HeidemanN, F. G; SALM, J. F. (orgs). Brasília: Unb, 2014.

FARIAS, C. A. P. A política de avaliação de políticas públicas. Revista Brasileira de Ciências Sociais, v. 20, n. 59, p. 97-169, 2005.

JONES, B. D.; TRUE, J. L.; BAUMGARTEN, F. R. Does incrementalism stem from political consensus or from institutional gridlock? American Journal of Political Science, v. 4, n. 41, p. 1319-1339, 1997. 
KAMLET, M. S.; MoWERY, D. C. Budgetary side payments and government growth, 1953-1968. American Journal of Political Science, v. 27, p. 636-664, 1983.

KING, G. The Future of Replication. International Studies Perspectives, 4, p. 443-499, 2003.

KING, G. Replication, Replication. PS: Political Science and Politics, 28, p. 443-499, 1995.

LEHMBRUCH, G. Liberal corporatism and party government. In: LEHMBRUCH, Gerhard; SCHMITTER, Phillipe. (eds.) Trends Toward Corporatist Intermediation. Sage, Beverly Hills and London, p. 147-185, 1979.

LINDBlom, C. The science of muddling through. Public Administration Review, v. 19, p. 79-88, 1959.

LINDBLOM, C.; HIRSCHMAN, A. O. Desarrollo económico, investigación y desarrollo, diseño de políticas. In: Democracia y sistema de mercado. México D.F.: Fondo de Cultura Económica, p. 284-311, 1999.

LINDBLOM, C. Muddling through 2: a ubiquidade da decisão incremental. In: HeidemanN, F. G; SALM, J. F. (orgs). Brasília: Unb, 2014.

LoWI, T. J. The end of liberalism: the second republic of the United States. New York / London: W.W Norton \& Company Inc. $2^{\text {nd }}$ ed, 1979.

MATIAS-PEREIRA. Administração pública comparada: uma avaliação das reformas administrativas do Brasil, E.U.A. e União Européia. Revista de Administração Pública - RAP, v. 42, n. 1, p. 61-82, jan./fev, 2008.

O'CONNOR, J. USA: a crise do Estado capitalista. Rio de Janeiro: Paz e Terra, 1973.

REZENDE, F. C. Por que as reformas administrativas falham? Rio de Janeiro: FGV, 2004.

Os leviatãs estão fora do lugar. Dados - Revista de Ciências Sociais, v. 39, n. 2, p. 195-2111996.

Pressman, J.; Wildavsky, A. Implementation. Berkeley: University of California Press, 1973.

SátYRo, N. G. D. Políticas nos estados brasileiros e gastos sociais: uma análise de série temporal com corte transversal - 1987 a 2002. In: SouZA, C.; NETO, P. F. D. (orgs.) Governo, políticas públicas e elites políticas nos estados brasileiros. Rio de Janeiro: Revan, p. 57-90, 2006.

SCHMITTER, P. Still the century of corporatism. In: LEHMBRUCH, G.; SCHMITTER, P. (eds.) Trends toward corporatist intermediation. Sage, Beverly Hills and London, p. 7-53, 1979.

SHARKANSKY, I. Agency requests, gubernatorial support and budget success in the state legislature. The American political Science Review, v. 62, n. 4, p. 1220-1231, 1968.

SıMon, H. A. Comportamento administrativo. 2o edição em português. Rio de Janeiro: Fundação Getúlio Vargas, 1971.

StRAUSSMAN, J. D. Rights-based budgeting. In: RUBIN, Irene (eds.) New directions in budget theory. New York: State University of New York, 1988. 
WANAT, J. The bases of budgetary incrementalism. American Political Science Review, v. 68, p. 1221-1228, setembro, 1974.

TRUE, J. L. Avalanches and incrementalism: making policy and budget in the United States. American Review of Public Administration, v. 30, n. 1, p. 3-18, 2000.

WILDAVSKY, A. The new politics of the budgetary process. Boston: Little, Brown. $2^{\text {nd }}$ ed, 1992.

The politics of the budgetary process. Boston: Little, Brown. $2^{\text {nd }}$ ed, 1979.

\section{Italo Fittipaldi}

Possui doutorado em Ciência Política pela Universidade Federal de Pernambuco (UFPE). Atualmente é Coordenador do Núcleo de Pesquisa Aplicada em Políticas Governamentais (NPGOV) e Professor do Programa de Pós-Graduação em Ciência Política e Relações Internacionais e do Programa de Pós-Graduação em Gestão Pública e Cooperação Internacional da Universidade Federal da Paraíba (UFPB). Contato: italofittipaldi@gmail.com

\section{Saulo Felipe Costa}

Possui doutorado em Ciência Política pela Universidade Federal de Pernambuco (UFPE). Atualmente é Bolsista PNPD-CAPES no Programa de Pós-Graduação em Relações Internacionais da Universidade Estadual da Paraíba (UEPB) e Pesquisador do NPGOV. Contato: s.felipe@hotmail.com

\section{Cletiane Medeiros Costa de Araújo}

Possui mestrado em Ciência Política pela Universidade Federal de Pernambuco (UFPE). Atualmente é Doutoranda em Ciência Política pela UFPE, Bolsista CNPq e Pesquisadora do NPGOV. Contato: cletiane.araujo@hotmail.com 